\title{
Produzindo o público e o privado no deslocar e no habitar: diálogos cruzados entre etnografias de práticas de caronas e de formações permaculturais no espaço urbano
}

Producir lo público y lo privado en el desplazamiento y el habitar: diálogos cruzados entre etnografías de prácticas de autostop y formaciones permaculturales en el espacio urbano

Producing the public and the private in displacement and living: crossed dialogues between ethnographies of hitchhiking practices and permacultural formations in urban space

Resumo

Desenhar fronteiras entre espaço público e privado nas cidades urbanas contemporâneas se articula com reflexões sobre a ação de intervenção do Estado para regulação do uso comum do espaço frente aos interesses e demandas de uso privado de indivíduos, grupos sociais, e/ou corporações. Se a posse coletiva dos espaços remete aos domínios de ação de diversos agentes monitorados pelo Estado em função de seu poder de governabilidade (Foucault, 2012), a apropriação privada dos espaços tende a ser associada a figura do indivíduo e a esfera de suas ações. A proposta deste trabalho surge do diálogo entre duas pesquisas etnográficas: uma sobre a prática de deslocamento de carona na cidade de Florianópolis (SC, Brasil) e a outra sobre as práticas de formação e construção de habitação permaculturais em Porto Alegre e Pelotas(RS, Brasil). Nos interessa pensar como estas podem vir a borrar
Renata Hilal

Universidade Federal

do Rio Grande do Sul,

Porto Alegre, Brasil.

\renatadhn@gmail.com

(1) ORCID: 0000-0003-3693-4529

$\checkmark$ Google Scholar

Yuri Rosa Neves

Universidade Federal de

Pernambuco, Recife, Brasil.

$\square$ nevyuri@gmail.com

(1) ORCID: 0000-0002-0996-6288

$\leadsto$ Google Scholar

Cómo citar este artículo:

Hilal, R. y Neves, Y. R. (2021). Produzindo o público e o privado no deslocar e no habitar: diálogos cruzados entre etnografias de práticas de caronas e de formações permaculturais no espaço urbano. Revista de Antropología y Sociología: Virajes, 23(2), 203-226. https://doi.org/10.17151/rasv.2021.23.2.10 
e desestabilizar fronteiras imaginadas/construídas entre o que é público e privado a partir de um olhar para as infraesutruturas (Star, 1999; Larkin, 2013).

Palavras chave: Infraesutrura; Carona; Permacultura; Agência; Público e Privado.

RESUMEN

Trazar límites entre el espacio público y privado en las ciudades urbanas contemporáneas se articula con reflexiones sobre la acción de intervención del Estado para regular el uso común del espacio frente a los intereses y demandas del uso privado por parte de individuos, grupos sociales y/o corporaciones. Si la propiedad colectiva de los espacios se refiere a los dominios de acción de diversos agentes monitoreados por el Estado por su poder de gobernanza (Foucault, 2012), la apropiación privada de espacios tiende a asociarse con la figura del individuo y el ámbito de sus acciones. El propósito de este trabajo surge del diálogo entre dos investigaciones etnográficas: una sobre la práctica del autostop en la ciudad de Florianópolis (SC, Brasil) y la otra sobre las prácticas de formación y construcción de viviendas permaculturales en Porto Alegre y Pelotas (RS, Brasil). Nos interesa pensar en cómo estas actividades pueden difuminar y desestabilizar los límites imaginados/construidos entre lo público y lo privado desde una mirada a las infraestructuras (Star, 1999; Larkin, 2013).

Palabras clave: Infraesutrura; Autostop; Permacultura; Agencia; Público y Privado.

\section{Abstract}

The effort to draw boundaries between public and private space in contemporary cities, is articulated through reflections on the State's action to intervene and regulate the common use of space in the face of the interests and demands of for the private use by individuals, social groups, and/or corporations. If the collective ownership of spaces refers to the domains of action of various agents monitored by the State due to its power of governance (Foucault, 2012), private appropriation of spaces tends to be associated with the figure of the individual and the sphere of his/her actions. The purpose of this text arises from the dialogue between two ethnographic researches: one about the practice of hitchhiking in the city of Florianópolis (SC, Brazil) and the other about the practices of formation and construction of permacultural housing in Porto Alegre and Pelotas (RS, Brazil). We are interested in thinking about how these activities can blur and destabilize imagined/constructed boundaries between what is public and private departing from the concept of infrastructures (Star, 1999; Larkin, 2013). 
Keywords: Infraestructure; Hitchhiking; Permaculture; Agency; Public and Private.

\section{A urbanização como uma infraestrutura e os domínios público e privado}

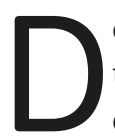
esenhar as fronteiras entre o que é público e privado não é uma tarefa fácil de ser cumprida, apesar deste esforço atribuir divisões aparentemente simples acerca das representações de espaços e territórios enquanto destinados para o uso coletivo ou individual. Ao lado disso, outra rápida associação é quanto as responsabilidades do Estado ou das iniciativas privadas sobre certos aspectos. Esta reflexão mobiliza desdobramentos produtivos ao pensarmos a vida nas cidades, pois as dinâmicas e ritmos colocam as pessoas em variados cruzamentos destas dimensões que, como argumentaremos, tendem a exibir uma permeabilidade e mistura daquilo que poderíamos considerar público ou privado. Este caráter será ainda reforçado por partirmos empiricamente de práticas não-hegemônicas de pedir e dar caronas no cotidiano de uma cidade (hacer dedo) e utilizar técnicas permaculturais na construção de casas. Nestes contextos, circulam materiais, ideais, pessoas e normas burocráticas, iniciativas estatais, empresariais e individuais de modo a abalar aquilo que poderia ser colocado normativa ou funcionalmente em dimensões de público e privado com fronteiras bem estabelecidas.

Antes de aprofundarmos nossas etnografias e exibir alguns destes jogos de relações, vamos introduzir algumas discussões nas ciências humanas que contextualizam estes conceitos em diferentes referentes, normativo/jurídico, funcional e subjetivo. Nesta digressão não pretendemos uma arqueologia conceitual exaustiva, a discussão nos interessa na medida que organiza e prepara o olhar para os efeitos da existência destas categorias se manifestando na vida das pessoas. Assim, o conceito de infraestrutura (Star, 1999; Larkin, 2013; Smith, 2016; Dalakoglou e Harvey, 2012) será chave tanto por esta perspectiva de questionar fronteiras de certas categorias e a efetividade esperada da modelagem dos espaços para criação de infraestruturas, convidando-nos a um olhar específico para a ideia de público e privado, quanto por permitir aproximar nossos campos de pesquisa, já que a mobilidade e as práticas de construção residencial são aspectos imersos numa visão infraestrutural. A partir daí desenvolvermos conceitos de menor alcance para pensar nossos contextos de pesquisas em interação. 


\subsection{Metamorfoses do público e do privado}

Historicamente, a origem do Estado moderno é um marcante referente para compreender os desdobramentos da relação entre aquilo que consideramos público e privado nos dias de hoje, pois ali se efetivou um esforço essencialmente normativo e jurídico de estabelecer definições a partir dos direitos e deveres entre o rei ou o soberano no controle do Estado e do poder, e o indivíduo privado em seu espaço e iniciativas. Os chamados autores contratualistas ou jusnaturalistas, como Hobbes, Rousseau e Locke, independente da preferência pela forma de governo (monarquia absolutista ou democracia) e de suas diferenças quanto às ideias primordiais daquele momento (estado de natureza, soberania, liberdade...), são ilustrações deste esforço político e principalmente jurídico visando proteção e defesa do direito à propriedade privada e das liberdades individuais em contraponto aos limites do poder. Neste sentido, algo que se incorpora depois nesta noção de público é a ideia de um povo específico sub o julgo da soberania, membros de uma nação em certo nível abstrata (Anderson, 2008) dentro de um desenho jurídico, normativo e burocrático (Herzfeld, 1992). Além disto, vale notar como esta preocupação se estende ao longo dos séculos e ressoa em pensadores contemporâneos vinculados principalmente à ciência política, como Habermas (2002) e Skinner (2005). Discute-se formas de participação e representações na vida política e pública, os limites ideais do exercício do poder do Estado e seus deveres, as liberdades individuais e seus locus exercício.

Outra maneira de observar esse binômio conceitual é em termos de uma funcionalidade prática articulada com aspectos materiais. Fazendo mais uma digressão, podemos notar como alterações na racionalidade do Estado, ou no seu "modo de ver", como diria James Scoot (1998), efetivadas durante o século XVIII e XIX, culminam numa produção intencional dos espaços com a função de exercer uma gestão e controle produtivo e populacional. Esta noção dialoga com o que Michael Foucault (2012) chamou de governamentalidade dentro da lógica do biopoder e coloca para a presente reflexão uma nova camada para pensar principalmente a consolidação da ideia de público enquanto espaços de controle dos governos e o Estado como um agente chave provedor do "interesse público". É ele que deve gerir o saneamento, fiscalizar e exigir parâmetros de funcionamento para indivíduos em suas residências e para as empresas em suas concessões. Algo próximo poderia ser dito sobre a mobilidade. 
Não há um corte entre aquilo que chamamos de compreensão normativa e funcional do público e do privado, mas uma evidente continuidade. Esta divisão heurística pretende mapear diferentes formas de observarmos os efeitos práticos na vida. Destacamos primeiro a existência enquanto nomos, um conjunto normativo que fala de pertencimento, de direitos e segue um regime ideológico com princípios como igualdade e imparcialidade. Segundo, chamamos atenção para a ideia de que o Estado tem a função de zelar pelo interesse geral, e para tal incide materialmente sobre o espaço.

Se estes sentidos mais normativos e funcionais nos parecerem essenciais para criar pontos de partida comuns para explorar nossas ideias, a antropologia pode ainda nos trazer uma visão mais subjetiva destes conceitos. Partindo da antropologia urbana e outros estudiosos de urbanidades, encontramos um proeminente interesse sobre como os diferentes espaços urbanos são produtores de efeitos subjetivos, do blasé de Simmel (1903 [2005]) ao flaneur de Benjamin (1994). O caráter público ou privado dos espaços, nesse sentido, pode ser capturado como territórios simbólicos, algo que fica bastante elucidado na discussão sobre o papel da casa e da rua na sociedade brasileira com DaMatta (1997). Espaços são então morais e simbólicos, subjetivamente elaborados. A partir destas noções, discute-se o redesenho destes fronteiras a partir de fenômenos como a velocidade da globalização, o neoliberalismo, a segregação, da cidades muradas, do individualismo (Augé, 1994, 2010). Cabe às ciências humanas exibir como os espaços coletivos são ao mesmo tempo habitados por grupos heterogêneos que compartilham diferenças fugazes, incertezas, acasos e memórias (Arantes, 2000; Proença, 2002; Eckert e Rocha, 2011, 2013). O que é central para nossa discussão a partir destas ideias é como os espaços públicos e privados não estão prontos nem dados, mas constantemente estão sendo praticados (De Certeau, 1994).

\subsection{Infraestrutura e o espaço urbano}

Ao fazer esta breve retomada pensando dimensões normativas, funcionais e subjetivas destes conceitos não buscamos escolher a mais importante ou definidora, mas considerar como estas coexistem e captam diferentes significados e aspectos que circundam a realidade de todos. Assim, a perspectiva infraesutrural é estratégica por pensar nos constructos conceituais através de seus efeitos, haja vista a sua continuidade epistemológica com uma antropologia da ciência (Latour e Wolgar, 1997) e tecnologia (Callon, 1998) na qual uma ideia de "causalidade" e performance de modelos, teorias e modelagens é central (Star, 1999; Larkin, 2013). E, neste sentido, o espaço urbano é um lugar privilegiado para perceber 
como materialidades infraestruturais incorporam conceitos e diretrizes com as quais as pessoas estão sempre em contato, exibindo então aspectos normativos e legais, distribuindo papéis e responsabilidades sobre a produção do espaço, e produzindo percepções sobre quais agentes devem gerir e dar conta de certas dimensões da vida. Smith (2016) argumenta que as cidades podem ser pensadas como criadoras de "consensos materiais" através do "engajamento" cotidiano da pessoas em atividades banais, algo que toca no que talvez seja um das principais ideias envolvendo o estudo das infraestruturas: sistemas de saneamento, de energia, de telefonia e transporte público devem funcionar de modo a parecem invisíveis na experiência (Star, 1999). Nesta direção, Graham e Marvin (2001) chamam atenção para naturalização destas materialidade na vida urbana quando damos descarga, colocamos o lixo na rua ou plugamos algo na tomada. Nestas situações "ativamos" toda uma rede de artefatos que se espalha muito além do ponto com o qual no relacionamos, acionando também toda a concepção abstrata e conceitual da modelagem técnica na qual aderimos sem refletir muito. Mas certamente não se trata de uma via de mão única, os usuários desafiam o planejado e muitas vezes redefinem formas de usar e compreender tais infraestruturas. Como argumenta Smith, a ideia de consenso remete a um diálogo, o que reforça este processo de negociação entre os que concebem e gerem, e as pessoas que a utilizam (Smith, 2016, p. 166).

Esta ideia de que as modelagens das infraestruturas são desafiadas pelo uso é chave para nosso encontro de etnografias e ideias, já que o foco sobre práticas não hegemônicas de mobilidade e de construção facilmente se colocam como contestação destes modelos, ainda que estejam "aliados" a eles de alguma forma. Por exemplo, por mais que prática de carona seja vista por um caráter político e crítico (Mahood, 2014; Keller e Silva, 2010), para sua existência precisamos de uma rede viária estabelecida e fluxo de automóveis, o que na maioria das vezes passa por esforços do Estado e de inciativas de empresas privadas. Assim, interessa-nos pensar como estes campos empíricos colocam em movimento essa série de articulações quanto ao engajamento material, à relação com modelagem e ao caráter de invisibilidade em torno da compreensão antropológica de infraestruturas, sabendo que os conceitos de público e privado são noções organizadoras da experiência com as infraestruturas, para gestores e usuários. Em especial, a discussão sobre a naturalização e invisibilidade se apresenta de modo profícuo na medida em que se considera que é a partir do colapso ou da quebra que uma determinada infraestrutura é visibilizada em sua extensão (Star, 1999). Como um cano que estoura, a energia que cai ou uma greve que paralisa algum serviço essencial, nestes momentos somos convidados a nos dar conta de toda a rede de pessoas, processos 
e artefatos materiais que mantém aquela infraestrutura funcionando. Não cabe, neste sentido, preocupar-se somente com o ato de construções técnicas de infraestruturas em um local particular, mas juntamente seguir estes projetos em diferentes fluxos, às vezes até mesmo longe de onde estão situados. Esta circulação etnográfica tensiona, então, as diferentes escalas entre o que é global e local ou - que mais nos interessa aqui - entre o que é público e privado 1 .

Nossa proposta, nas esteira da Larkin, é pensar que formas de vida e relação com os espaço emergem a partir do colapso (2013 p. 318). Como as pessoas dão sentido à estes acontecimentos a partir de suas perspectivas e relações com determinados infraestruturas. Outra ideia cara à nossa elaboração é quanto ao "fazer-se" do Estado em práticas e representações continuamente negociadas no cotidiano das pessoas (Sharma e Gupta, 2006), em lógicas de burocracia (Herzfeld, 1992) e de legibilidade (Scoot, 1998, 2006; Schuch, 2015), sabendo-o como grande provedor da material e conceitual das dimensões infraestruturais. Nesta direção, Mitchell (1999) critica a compreensão do Estado como entidade discreta separada da população, pois entende esta percepção apartada como parte de um "efeito estrutural" do próprio Estado, colocando-se num lugar transcendente das realidades mundanas. Ao contrário, o Estado está imerso em subjetividades e práticas cotidianas (p. 181)2. O "fazer-se" trata-se mais da imanência de olhares tanto de cima para baixo como de baixo para cima. Isto nos coloca como questões que normativa e funcionalmente podem parecer bem estabelecidas e separadas na vida contemporânea se tornam mais porosas e embaraçadas na prática. Assim, pensar na ideia de infraestruturas nos permitiu partir de aspectos materiais que podem desafiar e redesenhar a relação de conceitos e noções utilizadas banalmente no cotidiano.

Esta direção é potente para pensarmos as práticas de deslocamento por caronas e as práticas de construções de habitações permaculturais em cenários urbanos, na medida em que estes processos de habitar e deslocar apresentam desafios que visibilizam estes efeitos da governamentalidade

\footnotetext{
"Focusing on infrastructure also creates a conceptual space to examine the shifting boundaries between material and immaterial structures, and the shifting networks between assemblages of human and nonhuman actors. Furthermore, tracing infrastructure reveals power dynamics that transcend divides between public and private, state and NGO" (https://culanth.org/curated_collections/11-infrastructure, acessado no dia 16 de outubro de 2017).

"Rather than explain the form of the state as the consequence of the disciplinary regime of capitalist production, one can see both the factory regime and the power of the state as aspects of the modern reordering of space, time, and personhood and the production of the new effects of abstraction and subjectivity. It is customary to see the state as an apparatus of power and the factory as one of production" (Mitchell, 1999, pág. 181)
} 
na organização prática e conceitual da vida, e também a participação individual neste processo através da interação com as infraestruturas no ambiente. A carona em Florianópolis convive no espaço das ruas entre carros privados e transporte público, movimentando pessoas no cotidiano num acordo informal e fugaz. O engajamento nesta forma de movimento expressa efeitos que nos colocam a refletir sobre o paradigma do deslocamento entre a automobilidade e o ônibus, o que exige daqueles que pegam carona viver experiências na margem de ambos. Ou seja, qual o significado de abrir um espaço privado do carro para cumprir uma função vista como parte da gestão pública mobilidade? Construir casas permaculturais desnaturaliza formas convencionais de habitações e visibiliza como questões de interesse público invadem o espaço privado da casa, regulamentando saneamento, energia, normas técnicas de estrutura e materiais utilizados. Deparar-se com os desafios presentes nas edificações de uma casa permacultural tenciona estas fronteiras e atribuições de responsabilidades aparentemente estáveis entre o público e o privado, e assim nos convida a considerar com profundidade os processos de aprendizagens e experiências nestes contextos.

\section{Trajetos materiais: o habitar e a infraestrutura da água ${ }^{3}$}

Era Maio de 2014, um dia de domingo ainda nublado após muita chuva na cidade de Pelotas, Rio Grande do Sul, Brasil. Me encontrava na parte de acesso mais alta da $\mathrm{Casa}^{4}$, em cima da construção do "telhado vivo" que era edificado naquele momento. Lá de cima era possível observar uma ampla paisagem do entorno composta por casas, prédios baixos mais distantes, fios, postes, gramados descampados, ruas asfaltadas e de chão batido. Do outro lado da calçada havia uma larga canaleta por onde a água manuseada na Estação de Tratamento de Água do município passava. No seu trajeto, esta água encontrava logo à frente o Canal São Gonçalo fluindo até a Lagoa dos Patos. Normalmente, no nosso cotidiano, não conhecemos o processo de tratamento de água coletiva, ou seja, as etapas de vazamentos, os produtos utilizados e as técnicas implicadas. Particularmente, nunca soube exatamente de onde aquela água da canaleta vinha, mesmo ouvindo diariamente a sua pressão de evasão. Alguém muito interessado em entender este processo talvez soubesse partes dele. No entanto, o que era visivelmente compartilhado entre a maioria de nós, ao olhar aquela espuma produzida conjuntamente com a água, era a

\footnotetext{
A seção 2 deste artigo refere-se à experiência de pesquisa de Renata Hilal (2014, 2018).

O material etnográfico que acompanha a experiência da construção desta Casa faz parte de um trabalho de campo realizado durante os anos de 2013 e 2014 junto ao processo inicial de edificação. A Casa está localizada na cidade de Pelotas, Rio Grande do Sul, Brasil. A partir de agora sempre que aparecer "Casa" refere-se a esta experiência.
} 
garantia de que a limpeza e o tratamento estavam sendo executados por parte das entidades públicas.

O que gostaríamos de chamar atenção, por agora, é o fato de que estávamos fazendo algo muito parecido ao construir aquele "telhado vivo". Estávamos negociando relações específicas com a água, pensando seu trajeto a partir de um telhado voltado para a captação e tratamento de água da chuva e cuidado bioclimático da Casa. Entendemos, claro, que tratam-se de domínios diferentes de negociações, e isto é, justamente, uma das inquietação deste trabalho. Pensar a água enquanto uma infraestrutura de responsabilização nos leva a refletir o que ouvi de um permacultor em um curso que participei nas mediações de Porto Alegre, Rio Grande do Sul, Brasil": "Quando pensamos estas estratégias para a água não têm a prefeitura, você é quem resolve. Ao tomar banho, a água está conectada com a bananeira e com a chuva".

Conceito criado durante a década de 70 por Bill Mollins, a Permacultura pode ser definida como um conjunto de técnicas e conhecimentos agrícolas, construtivos e de gestão bioclimárica no qual o desgin ou a modelagem busca inspiração nos processos naturais dos ecossistemas. Por isso, uma ideia de "cultura permanente", preocupado com a integração ecológica local. Dentre estas técnicas, estão as de tratamento de água divididas em dois tipos: para "água cinza" e para "água negra". Todas as "águas cinzas" são aquelas que na sua composição não têm excrementos humanos, ou seja, águas vindas do uso da torneira, chuveiro, lavanderia, etc. O "círculo de bananeira" me parece ser a mais utilizada neste caso $^{6}$ : a saída de um cano enterrado é posicionado ao centro de um buraco profundo escavado no terreno. Dentro desta circunferência, muitos cascalhos, troncos de madeira e palha se misturam com o cano. Ao redor do buraco, as raízes de bananeiras plantadas interagem no processo bacteriano de limpeza. Através da transpiração desta espécie de vegetação, a água retorna tratada pro ar e pro solo. Já para a "água negra, a "Bacia de Evapo Transpiração" (BET) é mais utilizada. É uma técnica mais complexa, com uma bacia de concreto com várias camadas e, além de bananeiras, planta-se outras plantas que gostem de umidade como mamoeiros. 
Em junho de 2017 visitei uma casa, localizada na zona rururbana de Porto Alegre, Rio Grande do Sul, Brasil, que implementou no seu terreno uma BET para tratamento da água do banheiro. O morador e proprietário da casa contou que, depois de dois anos, a BET começou a produzir uma umidade diferente na terra, o que chamou a sua atenção. Nos próximos dias, ele precisaria abrir a BET e descobrir o que acontecia de fato com ela, fazendo deste processo de manutenção uma oficina de aprendizagem aberta ao público. Isto remete o que Scott (1998) sugere ao trazer o conceito de "metis". Para ele, "metis" denota o conhecimento que vem através da experiência prática. Ambas manutenção da BET e construção do "telhado vivo" criavam outras estratégias de uso de água que enfatizavam, exatamente, este tipo de conhecimento pela experiência. Os esquemas de engenharia social do "alto-modernismo", segundo Scott (1998, p. 309-342), não focam nas habilidades, inteligências e experiências de pessoas comuns. Ao contrário, criam mapas de legibilidade e controle para projetos que planejam facilitar a administração central da produção e atividade pública (Scott, 1998, 2006).

Numa conversa recente, uma amiga, que desconhecia até então técnicas permaculturais para "água negra" e "água cinza", relatou com surpresa a semelhança com a época de sua infância nos anos cinquenta. Era muito comum não existir banheiro fixo na casa. Somente depois de alguns anos que o governo passou a recolher e manejar uma espécie de cubo de madeira nas habitações onde se acumulavam os dejeto, lembrou ela. Como também passou a existir, mais frequentemente, o incentivo e a edificação de fossas sépticas conectadas com o banheiro. O movimento sanitarista ${ }^{7}$, que emerge com força nos anos vinte no Brasil, criou desde então diversas políticas coletivas para a salubridade. Através de reformas sanitárias, os espaços urbanos passam a ser reorganizados e os vínculos com a moradia são invadidos também por um conjunto de ações de controle de habitação (Perrot, 1992). A água, enquanto um possível agente epidemiológico, passa a ser regulamentada por decretos e incentivos de educação sanitária

\subsection{A Casa que vaza}

Retornando ao ato da construção do "telhado vivo", em Maio de 2014, acompanhei o relato da principal idealizadora e proprietária da Casa à um morador do bairro que ajudava no processo:

Esta é uma questão epidemiológica histórica e transnacional que está em contínuo debate e transformação, não temos como objetivo aprofundar a complexidade deste assunto neste trabalho. 
As pessoas estão acostumadas com uma forma de vida, com um tipo de arquitetura. Quando tu começa a usar outros materiais existe uma distorção na maneira de enxergar. Um preconceito. Tem uma senhora, uma vizinha da rua de trás, que nos perguntou se éramos nós que morávamos aqui. A gente disse que sim, então ela: "Ah, eu tenho uma pena de vocês, tenho uma pena do pessoal que mora nesta casa, um lugar horrível". (...) A nossa proposta, aqui, é usar nada do que está convencionalmente colocado. Trazer outras coisas e possibilidades. E perceber que está tudo bem, que você pode fazer isso. Construir um "telhado vivo" será bem interessante para as pessoas verem que existe esta opção, não precisa comprar uma telha de "brasilit". Tu pode de repente fazer um mutirão com a vizinhança, puxar terra pra cima da casa e plantar em cima dela. Tu vai ter um conforto termo-acústico muito melhor do que com a "brasilit", que faz um efeito totalmente contrário. No verão deixa muito quente e no inverno deixa a casa fria. Com o "telhado vivo" é diferente... No inverno mantém o calorzinho dentro de casa e no verão refresca. Repensar algumas coisas, sabe, estamos acostumados a repetir o padrão e, então, tu descobre que não precisa. Você pode fazer de outro jeito. (Transcrição de fala a partir de um registro audiovisual, 5 de julho de 2014)

Desde o início da construção da Casa, percebi que alguns daqueles que passavam e a avistavam criavam níveis de relação com ela, emergindo controvérsias e imaginações. Existia, por parte de habitantes e transeuntes do bairro, um olhar atento sobre ela. Investiguei o que a Casa suscitava, buscando conhecer vozes e olhares que surgiam e, por vezes, cruzavam-se. As pessoas acompanhavam o desenvolvimento da construção e seus relatos mostravam como a Casa produzia intersecções de trajetos coletivos e particulares. A Casa, ao destoar e se diferenciar do entorno, dava início à constituição de uma personagem identificada:

A primeira vez que eu vi, foi num caminho. Às vezes, eu passo por dentro do bairro que tem ali atrás e então eu chego à rua da Casa. No início eram só umas madeiras, já tinha um andar estabelecido. Com isso, eu comecei a reparar, pois era uma construção distinta do que tem ao lado. Com o tempo foi se desenvolvendo e eu fui acompanhando e junto imaginando o que poderia ser. Me veio uma lembrança de infância, de Casa da Árvore. Eu sinto que acompanhei o desenvolver, do primeiro andar até existir o último, e agora já há um telhado. (Transcrição de um discurso em um registro audiovisual para um transeunte, 5 de Julho de 2014) 
Alguns imaginavam ainda a construção para ser moradia de grupos definidos como hippies, índios ou circenses. Outros acreditavam que na construção não se fixaria exatamente uma Casa ou que o espaço seria uma ocupação de estudantes e nele se construiria uma república ou mesmo um acampamento. Como já discutimos acima, o interesse público invade a casa através de suas regulamentações e serviços, mas aqui é também a Casa que invade o mundo. Através da diferença e do desajuste, está Casa passou a produzir múltiplos choques de criações imaginativos e sensoriais ligados às habitações no espaço. Larkin (2013) nos convida a perceber como a estética e a poética da infraestrutura podem manifestar outros meios por onde o político se constitui e se torna visível ${ }^{8}$. Neste sentido, para além de seguir as forças materiais que criam infraestruturas, também se torna produtivo traçar o campo afetivo que gera e desperta projetos infraestruturais, entendendo que os sentimentos também podem ser profundamente políticos (Larkin, 2013).

Por onde já circulei, é muito comum a problematização do que é legalmente permitido ou não nas construções em permacultura. Principalmente em zonas urbanas, onde diretrizes e normas regem com mais força a engenharia do uso de materiais e técnicas específicas. Os exemplos de como outros países aprovaram políticas públicas de incentivo ao uso de técnicas permaculturais são recorrentes nas minhas etnografias (Hilal, 2014, 2018). Aparecem tanto para justificar os usos destas técnicas quanto para pensar a regularização destas construções através da sua legibilidade frente ao Estado (Scott, 1998; Schuch, 2015). Recentemente soube que a Casa se tornou uma ONG, o que me sugere ser uma estratégia encontrada pelos idealizadores para dar conta desta diferença habitacional e do próprio papel que a Casa foi tomando dentro das relações cotidianas com o entorno (Hilal, 2014). Institucionalizada, facilita a captação de renda em editais e amplifica a sua relação com o entorno. Quando estive participando desta edificação, entre 2013 e 2014, lembro que umas das alternativas, caso houvesse problemas de regularização, era transformar o projeto numa obra de arte.

\footnotetext{
Larkin (2013) descreve breves exemplos etnográficos que sugerem ver as relações afetivas de fascínio ou temor sobre as infraestruturas. A implementação de uma estrada no Paquistão, por exemplo, emerge a maneira como aquele projeto de edificação infraestrutural não se ajustou aos paquistaneses por ser muito "moderno". O projeto da construção da estrada representou, assim, tanto a promessa como o fracasso. Outro exemplo traz a construção de um conjunto de habitações num condomínio fechado na cidade do Congo, México. Tal projeto produziu a desapropriação forçada de um assentamento urbano. Além de evidenciar a violência do Estado por trás dessa prática de "modernização", um dos moradores do assentamento urbano se reconheceu vítima deste processo mas também manifestou um olhar de encantamento sobre a futura construção habitacional, pois ela representava algo bonito e desenvolvido.
} 


\section{Deslocando-se de carona por Florianópolis ${ }^{9}$}

A paisagem típica de carona é a beira de estrada. Natureza contínua cortada por linhas longas de asfalto. Pegar carona é uma situação que pede uma postura atenta à todas variações contextuais, a passagem dos carros, uma possível chuva, riscos de assalto ou assédio. Em suma, é uma postura necessária para a abertura ao acaso e ao infinito de possibilidades (Laviolette, 2014). A carona espontânea ${ }^{10}$ num contexto urbano como Florianópolis, capital do estado de Santa Catarina no Brasil, difere da maioria das experiências de pesquisas sobre a prática em deslocamentos intermunicipais (Carlson, 1972; Purkins, 2012; Laviolette; 2014; Kendall, 2016). Consideraremos as particularidades de cenário.

A maior parte do território de Florianópolis está numa ilha com muitas barreiras naturais, como dunas, lagoas, morros e mangues. Assim, a urbanização produziu um padrão descontínuo de ocupação, resultando na formação de diversas 'ilhas' urbanas cercadas por estas barreiras e, na esmagadora maioria dos casos, ligadas por uma ou duas vias. Diferente do padrão quadriculado e mais interconectado das grandes cidades, o sistema viário tem uma forma de "espinha de peixe" (Reis, 2012. p. 134), desenho que remete ao de rodovias entre cidades. A concentração de fluxo facilita a carona, haja vista a facilidade de saber a direção de motoristas e carneiros, como numa estrada. Por outro lado, trata-se de uma sistema viários de baixíssima integração (Meideiros, 2006), o que gera muito trânsito e dificuldade de locomoção de ônibus, ainda mais na temporada turística quando a cidade chega quadruplicar sua população.

Esta urbanização e seu sistema viário são frutos do modo específico com que o espírito de reformas e modernização durante o século XX foi vivido ali. Nos anos 20 e 50, enquanto grandes cidades do Brasil fazem transformações audaciosas nos sistemas viários derrubando bairros, criando avenidas, integrando subúrbios e cidades satélites, em Florianópolis este processo foi restrito à região central da Ilha (Conceição, 2015), onde estava a poder político do estado, uma classe de trabalhadores dos serviços e algumas populações mais marginalizadas no seus arredores. O grande marco da construção civil até os anos 50 foi a ponte que finalmente ligava a capital ao continente. Somente a partir dos anos 60 e 70, com alguns estímulos como a criação de duas universidades

\footnotetext{
E seção 3 deste artigo se refere à experiência de pesquisa etnográfica de Yuri Rosa Neves (2018).

Consideramos por espontânea caronas em acordos informais e realizados entre carros na passagem e pessoas com dedo esticado na beira da via, diferenciando-se daquelas que são programadas por sistemas de informação, Facebook ou outros aplicativos. Para uma revisão dessas últimas no Brasil sob o rótulo de mobilidade ligada a economia colaborativa, ver Figueira (2015).
} 
públicas, da empresa pública de energia e a definição do potencial turístico como principal motor econômico, é que se intensificou um processo de integração entre bairros hoje centrais no crescimento da cidade. Neste momento, a migração interna do país para Florianópolis começa crescer.

O padrão de urbanização partindo do centro da Ilha fez com que a "cidade" paulatinamente se aproximasse das "freguesias"11, regiões de ritmos mais rurais ainda marcadas por uma economia agrícola e pesqueira (Reis, 2012; Rial, 1988). Isto permitiu relativa autonomia destas ilhas urbanas, desencadeando a prática da carona como opção de deslocamento a partir das sociabilidades entre moradores nativos e da falta de transporte público (Rial, 1988, p. 47-50)12. Até hoje, ao circular pela infraestrutura de vias a partir do centro urbano em direção aos extremos, vemos a continuidade deste processo. Na continuidade de paisagens mais rurais, estão outras urbanizadas. Atualmente, a carona em Florianópolis cumpre alguns movimentos diários de trabalhadores, estudantes, turistas, jovens, idosos, nativos e pessoas de "fora" que migraram para lá. O intenso processo de crescimento populacional ${ }^{13}$ trouxe não só novos atores em contato com a prática, mas significados e discursos relativos ao habitar a cidade.

\subsection{Colapso da infraestrutura ou a infraestrutura do colapso}

Era uma terça-feira chuvosa de 2013, começo de tarde. Pedia carona no último ponto de ônibus da Av. Pequeno Príncipe antes da praia. Apontava na direção da rodovia geral. Precisava ir ao centro e os trabalhadores do transporte coletivo estavam em greve. Havia um quebra mola na via que permitia um contato mais longo no cruzamento de olhares. A chuva se intensificava e um senhor sozinho numa pequena caminhonete com dois lugares atendeu meu apelo e parou. Me aproximei e lhe disse meu destino. Parecia estar trabalhando pelos papéis e notas no painel do carro. Disse que não iria até o centro, mas parte do meu caminho. Entro e agradeço a sua disposição, recebendo apenas um aceno leve como resposta. Ele mantém o olhar na via. Estava iniciando

1 "Freguesia", conceito êmico da Itha que se refere a como eram chamados o que atualmente são considerados bairros.

12 Rial (1988) reflete sobre a produção do espaço social na Lagoa da Conceição, bairro hoje internacionalmente conhecido como polo turístico. A primeira linha de ônibus foi implantada em 67. Antes disto, a locomoção era combinada com proprietários de carros que iam ao centro. A autora relata a existência do mesmo processo no bairro vizinho (p. 47)

13 De 1991 até 2010 a população quase dobrou, 255 mil para 421 mil pessoas, e a última estimativa do IBGE em 2016 é de que 477 mil pessoas estão residindo no município. Entre 2010 e 2016 se verifica um crescimento populacional de $13 \%$ ao ano, enquanto Porto Alegre-RS apresenta $5 \%$. Atualmente mais da metade da população é de pessoas de "fora" ou seus descendentes. 
minha primeira fase de pesquisa e, logo que arrancamos, começo a perguntar de onde era, se estava rodando a trabalho e em qual região morava. Com respostas diretas, ele contou que era "nativo"14 da Ilha e trabalhava numa ferragem, morava ali mesmo no Campeche, bairro onde estávamos. Ficamos um tempo em silêncio e, para quebrar o gelo, reafirmei meu agradecimento pela dificuldade de locomoção naquele dia com a greve do transporte. Ele assentiu e, depois de uma pausa, disse: "assim fica muito difícil mesmo". Relata que já não dava muitas caronas pois a cidade tinha mudado demais, porém "ainda se pode fazer isto" numa situação como aquela. Mantendo os olhos no caminho, ele não demonstrava muita excepcionalidade na situação ou interesse sobre quem eu era e para onde estava indo. Talvez fosse óbvio pra ele eu ser estudante de fora, personagem típico da ilha. Ao fim da carona, me deixa em frente a um supermercado mais ou menos $6 \mathrm{~km}$ de onde tínhamos partido.

Laviolette discute a carona como experiência "estocástica" pelo seu caráter aleatório e imprevisto de encontros, requerendo da pessoa uma adaptação lidando com a sensação de "suspensão" (2014). De fato, a fugacidade do acordo e do encontro requer decisões rápidas com o "descortinar"15 das situações, pois muito acontece num cálculo em instantes. Desde ponderar questões simples como se pegamos uma carona com um destino um pouco fora do objetivo, mas certeira, ou esperamos outra, até outras mais radicais como tentativas de assédio. Além disso, precisamos estar dispostos àquele contato e arriscar um deslocamento sem garantias de duração e companhia. Assim, coloca-se uma tensão entre a confiança ao abrir e entrar no espaço privado do carro e as incertezas que podem surgir no caminho. A maneira de controlar minimamente isso é impor contingências: não pego/dou carona à noite, para homens ou só dou quando tem uma greve.

Na urbanidade, compartilhamos certos ritmos que aproximam as experiências e permitem uma sensibilidade para o que afeta coletivamente as pessoas na cidade, como a greve na justificativa deste senhor. Contingenciar a carona a isto parece refletir sua vivência do crescimento e da diversificação populacional de Florianópolis como nativo. Neste sentido, cumpre uma ênfase utilitária de dar conta da demanda do transporte público que normalmente funciona. Então, tornei-me mais visível à

"Nativo" é uma denominação autodenominação das pessoas que nascem na Itha de Florianópolis.

Descortinar fora o termo que cunhei para pensar essa constante reconfiguração das situações na carona como se fossem a imagem de cortinas se abrindo e revelando novos elementos. Seguindo um pouco a metáfora de "suspensão", esta noção pretende tratar da temporalidade específica da prática de carona (Rocha e Neves, 2019) 
ele como parte ou usuário daquela infraestrutura, mesmo que eu pegasse poucos ônibus naquele tempo, carona era sempre mais fácil. Falar que só assim "ainda" é possível sugere também que num futuro próximo a prática da carona não será viável de nenhuma maneira naquele contexto.

Gostaria de trazer uma nova situação que, apesar da concordância sobre o "ainda" ser possível, nos convida a pensar a construção de outro horizonte de contingências que justifica a abertura do espaço privado do carro. O cruzamento destas experiências permite aprofundar nossa reflexão sobre "colapsos", carona e urbanização.

Pedindo carona para universidade num começo de tarde de 2013, um carro com uma mulher, Ângela, e seus dois filhos para. Logo que me aproximei do carro, a vi arrumando o banco e se preparando para minha entrada. Parecia estar um pouco nervosa. Disse que ia até a Lagoa da Conceição, metade do meu caminho. Aceitei a carona, entrei no carro e nos apresentamos melhor. Agradeci sua disposição, e ela logo disse ser a primeira vez que dava carona a um homem. Morava em Florianópolis há quase um ano, desde que seu esposo fora transferido. A prática da carona era nova para ela. "Em São Paulo isto seria impossível, mas aqui ainda dá". Continuamos a conversa sobre o processo de mudança e adaptação ao ritmo mais tranquilo de Florianópolis. Íamos na direção da creche de seus filhos, pouco antes do centro da Lagoa da Conceição. Chegando lá, Ângela desceu com os dois e eu esperei sozinho no carro por 3 ou 4 minutos. Quando retornou propôs me deixar direto no meu destino indo por outro caminho. Talvez me tomasse menos tempo pegar outra carona dali, pois ela precisaria retornar e passar novamente por onde viemos. Mas a garantia de seguir numa só carona até onde precisava e a empolgação com a conversa me fizeram aceitar a proposta. Meia hora depois cruzamos o ponto inicial do nosso encontro e seguimos pelo caminho que dá volta pela outra face do morro que precisava contornar.

A convergência desta mulher e do senhor sobre o "ainda" sugere que carona figura num horizonte finito da urbanização. Uma hora a cidade cresce e não dá mais. Ângela em especial escancara como a prática é possível ali pelas dinâmicas específicas do contexto de Florianópolis, São Paulo seria impossível. Porém, cada um se posiciona a partir de sua trajetória particular, e com isso apresentando diferentes significados e relações com a prática. Se no caso do senhor a carona é por causa da greve de transporte, algo externo que deu novos configurações de possibilidades, no relato com Ângela percebemos a importância das aprendizagens sobre as contingências situacionais nesta forma de deslocamento. Era a primeira vez que dava caronas para um homem, descobria a prática numa 
postura mais aberta, alargando as fronteiras de sua experiência. Ela estava mantendo viva a carona na cidade para além da falta de ônibus e do sentido mais utilitário, participa aprendendo a lidar com os riscos e as incertezas de abrir o espaço privado do seu carro para alguém desconhecido ${ }^{16}$. Vive isto não como alguém que viu a transformação de Florianópolis, mas como alguém que, a partir de sua vinda de um contexto muito mais urbanizado, evidencia a carona pela potência criadora de novos pertencimentos com um outro ambiente.

Certamente o processo de urbanização "ilhada" dos bairros que trouxemos anteriormente se reflete na mobilidade da cidade e na continuidade da carona como possibilidade. Não só a carona, mas outras dinâmicas de encontros e fluxos se entrelaçam com a materialidade da infraestrutura nesta cidade. Neste sentido, ao considerarmos o "ainda" ser possível a prática da carona - expresso pelo senhor e pela Ângela - nos permite evocar um ideal imaginário de vida urbana no qual experiências de sociabilidade como a carona são colapsadas. Ou seja, se num primeiro momento apontamos como no colapso de um transporte público a carona emerge, a intensificação da urbanização parece indicar a impossibilidade desta prática. Por exemplo, um dos efeitos da construção de viadutos na cidade é o fim de alguns pontos de carona, pois se perde o contato pela alta velocidade e pelas barreiras. A próxima carona se passa num lugar em que este é o caso.

\subsection{Efeito burocrático e os deslocamentos}

Era começo da tarde, fazia sol e eu pedia carona no trevo do Rio Tavares. Lugar movimentado, com posto de gasolina, supermercado, restaurante e variados comércios. Encontro de fluxos do Sul da Ilha e do Leste Ilha que iam ou retornavam da região mais central da cidade, na margem Oeste da Ilha. Como de costume, pedia carona no recuo de entrada do posto de gasolina, pouco antes de uma parada de ônibus. Atento aos diferentes carros no intenso movimento, com o dedão esticado, escuto alguém me chamando. Viro na direção da parada de ônibus e uma senhora me acena. Vou me aproximando com olhos e dedo atentos à via. Com o intenso barulho, não entendo bem o que estava falando, penso se a minha mochila estaria aberta ou se já nos conhecíamos. Chegando próximo o

\footnotetext{
A relação entre gênero e carona talvez demonstre com mais facilidade como diferentes perspectivas lidam com riscos diversos, produzindo experiências heterogêneas nesta forma de deslocamento. Muitas vezes escutei relatos de assédio em caronas sofrido por mulheres, o que motivava posturas e estratégias desde ser mais "seca" e direta, perguntar o destino do motorista antes de entrar para evitar "favores" desnecessários, restringir-se a certos horários, até mesmo deixar de pegar caronas sozinhas. De certo modo, reflete condição estrutural que coloca as mulheres em situação de constante cuidado com o risco de violência contra seu corpo.
} 
suficiente, ela diz: "não precisa pegar carona, pago tua a passagem". Fico surpreso com a gentil oferta. Agradeço e, cordialmente, digo que tenho dinheiro e estava pegando carona por outros motivos. Não tinha tempo para me explicar melhor, o fluxo de carros e os compromissos não permitiam desviar o foco da rua. Pela sua expressão, ela parecia não entender bem porque preferia a carona. Eu estava negando uma gentileza, havia um ruído na nossa comunicação, um instante de estranheza. Ela volta pra parada e logo pego uma carona. Como esperava pela dificuldade de locomoção sempre presente naquele trajeto, cheguei mais rápido do que se tivesse ido de ônibus.

Podemos dizer que, quando estamos num ônibus, a interação com desconhecidos não é a regra, ocorre quando algo foge do comum. Oferecer dinheiro produziu um contato que não precisávamos, e expressa uma leitura da minha opção enquanto necessidade pela pressuposta falta de grana para a passagem, como se não estivesse escolhendo pegar carona. Nos remete à motivação do senhor ao dar carona pela falta de ônibus, foca na utilidade. Este último relato permite aprofundar como a prática tensiona a dimensão da mobilidade entre o carro privado e o transporte público no paradigma urbano. Permite ressaltar mais o papel da lógica da indiferença, do uso do dinheiro e do tempo cartesiano presentes nos modelos e modelagens específicas deste ideal. Ao me oferecer dinheiro, esta senhora parece expressar inquietação de estar me locomovendo através de uma lógica que sai da indiferença, pois na carona tudo parece produtor de diferenças. Se no ônibus ou no carro privado o cálculo é sempre quantitativo -quantas pessoas? quanto custa? quantos carros por minutos numa via?- e relativo à propriedade -ter dinheiro para a passagem ou ter um carro-, na carona o cálculo é mais contingente e qualitativo: sempre nos tornamos alguém, importa com quem vamos, a hora que vamos, etc.

A carona requer aprendizado e disposição para sair do conforto da impessoalidade e do isolamento. Por isso, contrasta com o aprendizado de pegar um ônibus. Provavelmente conseguimos nos locomover em qualquer cidade do mundo seguindo o "trajeto burocrático" de esperar no ponto certo, pagar uma passagem e descer no destino. Utilizando um guia com horários e rotas, podemos ainda viver esta experiência sem mesmo realizar nenhum contato. Ou seja, utilizar transporte público sugere uma lógica de aprendizado replicável e facilmente compreensível a um estrangeiro que não conhece as dinâmicas locais (Scoot, 2006). Em "A Produção Social da Indiferença", Herzfeld (1992) discute como a burocracia pode ser compreendida pelo compartilhamento simbólico entre burocratas e a população de "clientes" "(...) de um universo maior que poderíamos 
chamar, quase simplesmente, a ideologia e prática de responsabilidade" (Herzfeld, 1992. P. 3) $)^{17}$, enfatizando assim a descida da lógica estatal ao cotidiano. O caso desta senhora que me ofereceu dinheiro, diferente do colapso, poderíamos falar em curto-circuito no regime ideológico, visibilizando a aderência das pessoas aos modelos e modelagens burocratizastes das infraestruturas.

\section{Habitações e deslocamentos do público e do privado}

Iniciamos este trabalho sugerindo como não é simples desenhar fronteiras entre o que é público e privado. Ao refletir sobre as nossas etnografias, buscamos mostrar como estes domínios, em suas diferentes significações, estão em constante cruzamento e negociação. Assim, buscamos realizar uma operação recorrente na antropologia de tensionar conceitos e modelos vinculados fortemente ao mundo dos especialistas com a sua manifestação ordinária (Star, 1999; Smith, 2016; Neiburg, 2007). Ao utilizarmos as metáforas do habitar e do deslocar, tentamos subverter o binário público e privado e, assim, fugir da possibilidade de simples reificação que nos dizem até onde agimos a partir da liberdade individual e do interesse público, até onde vai o meu espaço privado e minhas possibilidades no espaço público, abrindo então a reflexão para os variados aspectos que compõem estas duas dimensões práticas da vida. Entendemos estes domínios também de maneira fluída: a Casa não está contida em suas paredes, ao contrário, a sua materialidade vaza deslocando o entorno, gera curiosidades, empatias e penas; a carona não é somente uma prática de deslocamento, mas nos diz também das subjetividades habitam os espaços e fluxos da cidade.

Um dos principais trunfos de nossos objetos empíricos, e que os aproxima, é o fato de serem práticas não hegemônicas e facilmente enquadradas com críticas e politicamente orientadas. Assim, elas tenderam a servir de contrastes em relação as diretrizes de burocratização e a racionalidade estatal dispersas no cotidiano e imanentes às infraestruturas, formas de controle e gestão das populações e espaços. Mais especificamente, visibilizam os engajamentos das pessoas com estas dimensões em suas naturalizações e invisibilidades. A estranheza e desajuste em alguns relatos como ter "pena" dos moradores da casa ou pressupor a falta de dinheiro para pegar carona pode ser visto pela profundidade subjetiva destes modelos de convivência e formas hegemônicas de morar e se mover.

No original "If one could not grumble about "bureaucracy," bureaucracy itself could not easily exist: both bureaucracy and the stereotypical complaints about it are parts of a larger universe that we might call, quite simply, the ideology and practice of accountability." (Herzfeld, 1992. P. 3). 
Por isso, ambas experiências iluminam meios por onde o efeito estrutural do Estado (Mitchell, 1999) e o político se manifestam no ordinário.

A ideia de colapso é central nesta ideia, pois como argumentamos no início, na discussão antropológica sobre infraestrutura esta noção exibe o vínculo de engajamento e naturalização com estas materialidades. O caso da greve dos transporte é bastante alinhado com esta ideia demonstrando o compartilhamento coletivo do efeito desta paralização, sensibilizando o senhor e permitindo que a carona emerge desta situação como possibilidade (Larkin, 2013, p. 318). Por outro lado, se consideramos o caráter perspectivo das infraestruturas, a ideia de que uma escada, por exemplo, pode ser uma barreira para alguém numa cadeira de rodas e uma simples passagem para outras pessoas (Star, 1999), ou ainda como uma greve do transportes afeta diferentemente aqueles que tem carro e aqueles que não tem, nossas etnografias podem trazer outra camada para reflexão.

Praticantes da permacultura, como a construtora da Casa, ao colocarem suas escolhas em contraponto ao referente do normal e do convencional, exibem uma percepção sobre este mesmo normal enquanto algo problemático e insustentável para ambiente. Em certo sentido, a permacultura pode então ser vista como uma reação à visão de que as infraestruturas hegemônicas estão colapsando. Assim, se aproxima do inevitável caminho do fim da carona na urbanidade, o "ainda" pode dos relatos das primeiras caronas. Novamente, estamos trabalhando com referentes temporais coletivos que incitam práticas e percepções variadas. No caso das pessoas praticando permacultura, ao invés de um 'ainda' que parece aceitar o processo como dado e inevitável, há um horizonte em aberto do futuro que visa mudanças. Em ambos os casos, depende da perspectiva em relação a infraestrutura para incitar uma prática.

Ao longo do desenvolvimento deste trabalho, percebemos noções de temporalidade se manifestando de formas variadas. Se de um lado há estes tempos coletivos e processos vistos como inexoráveis ou como projeções de mudanças, nos quais explicitam os referentes sociais e significados compartilhados, há também uma dimensão temporal individual na medida em que a responsabilização sobre questões que convencionalmente são tidos de interesse público e de trabalho da gestão estatal recaem sobre o indivíduo. Existe aí nuances de como os tempos individuais tocam num caráter de emergência e criatividade (Deleuze e Guattari, 1997) de lidar com inacabado, reparos e com processos não garantidos. "Não tem prefeitura" quando se pensa estas técnicas para água, como mencionou o permacultor. Assim, estas práticas não hegemônicas se relacionam com os compassos coletivos com potencial de redesenhar as possibilidades 
de fronteiras entre, por exemplo, aquilo que é visto naturalmente como responsabilidade pública e privada.

Aproximar estes dois trabalhos etnográficos nos convidou a desnaturalizar conjuntamente formas de habitar e deslocar. Compreendemos que não se trata de tornar a construção de casas permaculturais ou a prática de carona em Florianópolis estanques à margem destas forças hegemônicas e estatais, seus modelos e modelagens. Buscamos trazer como estas duas práticas participam também da produção cotidiana e imanente do Estado, funcionando como contraponto e podendo até mesmo incitar o seu alargamento e seus limites (Das e Poole, 2004; Schuch, 2015) -como nos mostra a busca por regulamentação e políticas de incentivo ao uso de conhecimentos permaculturais.

\section{Agradecimentos}

Diversos agradecimentos são necessários. Primeiro ao Eduardo Dullo pelo incentivo à escrita coletiva; aos participantes da mesa "Retóricas del espacio público y producción del espacio urbano desde las resistências" na III Jornadas Internacionales de Antropología del Conflicto Urbano em 2017 por seus valiosos comentários numa versão inicial deste artigo, ao grupo de estudos sobre elites e infraestrutura do PPGA da UFPE (Programa de Pós-Graduação em Antropologia/Universidade Federal de Pernambuco) pela leitura atenta e sugestões (Alex Vailati, Ana Kurowicka, Alvaro Prado e Eloah Vieira), e aos pareceristas e editores da revista Viarajes. Agradecemos também à CAPES (Agência de Coordenação de Aperfeiçoamento Pessoal de Nível Superior) pelas bolsas concedidas durante o desenvolvimento das pesquisas aqui utilizadas para a reflexão.

\section{Referências Bibliográficas}

Augé, M. (1994). Não-lugares: introdução a uma antropologia da supermodernidade. Campinas: Papirus.

Augé, M. (2010). Por uma antropologia da mobilidade. Edufal Unesp.

Anderson, B. (2008). Comunidades Imaginadas. Reflexões sobre a origem e a difusão do nacionalismo. Companhia das Letras.

Arantes, A. A. (2000). A guerra dos lugares. Mapeando zonas de turbulência. Em A. Arantes. Paisagens paulistanas. Transformações do espaço público (pp. 104-129). Editora da Unicamp.

Benjamin, W. (1994). O Narrador. Magia e Técnica, Arte e Política - ensaios sobre literatura e história da cultura. Obras escolhidas. (Vol. I, $2^{\text {a }}$ ed.). Editora Brasiliense. 
Callon, M. (1998). El proceso de construcción de la sociedad. El estúdio de la tecnologia como herramienta para el análisis sociológico. Em M. Domènech e F. X. Tirado (Orgs.). Sociología simétrica: ensayos sobre ciencia, tecnologia y sociedade (pp. 143-170). Gedisa.

Carlson, D. (1972). Thumbs out: Ethnography of Hitchhiking. Em J. P. Spradley e D. W. McCurdy (eds.). The Cultural Experience: Ethnography in Complex Society (pp. 137-146). SRA. https://archive.org/stream/culturalexperien00spra\#page/146/mode/2up

Conceição, M. L. (2015). O Topocídio da Ponte Hercílio Luz. Resgate - Rev. Interdiscip. Cult., 23(2), 119-130. https://doi.org/10.20396/resgate.v23i30.8645811

Dalakoglou, D. e Harvey, P. (2012). Roads and Anthropology: Ethnographic Perspectives on Space, Time and (Im)Mobility. Mobilities, Routledge, 7(4), 459-465. https://doi.org/10 $.1080 / 17450101.2012 .718426$

Da Matta, R. (1997). A casa e a rua: espaço, cidadania, mulher e morte no Brasil. (5 $5^{\mathrm{a}}$ ed.). Rocco.

Das, V. e Poole, D. (2004). Anthropology in the Margins of the State. School of American Research Press.

De Certeau, M. (1994). A invenção do cotidiano: Artes de fazer. Vozes.

Deleuze, G. e Guattari, F. (1997). Mil Platôs: capitalismo e esquizofrenia 2. (Vol. 4.) (S. Rolnik, Trad.). Ed.34.

Eckert, C e R., Carvalho, A. L. (2011). Etnografia da duração nas cidades em suas consolidações temporais. Política E Trabalho, PPGS-UFPB. Revista de Ciências Sociais, 34, 107-126. https://periodicos.ufpb.br/ojs/index.php/politicaetrabalho/article/view/12185

Eckert, C. R. e Carvalho, A. L. (2013). A etnografia da duração. Marcavisual.

Figueira, G. M. (2015). Mobilidade colaborativa no Brasil: um estudo de caso sobre as iniciativas de carona na economia colaborativa. Anais do Congresso Nacional em Excelência de Gestão, 13-14.

Foucault, M. (2012). Cap. 17. A Governabilidade. Em M. Foucault. Microfísica do Poder (pp. 407-431). Graal.

Graham, S. e Marvin, S. (2001). Splintering Urbanism: Networked Infrastructures, Technological Mobilities and the Urban Condition. Routledge.

Habermas, J. (2002). A Inclusão do Outro. Edições Loyola.

Herzfeld, M. (1992). The social production of indiference. Exploring the symbolic roots of Western bureaucracy. The University of Chicago Press.

Hilal, R. (2014). Casa da Árvore: um estudo sobre a construção de uma Casa viva. Trabalho de Conclusão de Curso de Ciências: Universidade Federal de Pelotas, Pelotas - RS.

Hilal, R. (2018). Encontros com a permacultura: etnografia de aprendizagem entre lugares (Dissertação de Mestrado). Federal do Rio Grande Sul, Porto Alegre - RS.

IBGE, Cidades. Censo 2016. http://www.ibge.gov.br

Keller, M. C. e Silva, E. do N. (2010). Carona: uma alternativa para a mobilidade urbana em Florianópolis. Mosaico Social - Revista do Curso de Ciências Sociais da UFSC, 5, 204-219.

Kendall, P. (2016). Sharing the Road: The Post-Internet Hitchhiker. Journal of Visual and Media Anthropology, 2(1), 40-55. https://www.academia.edu/36280465/Sharing_ the_Road_The_Post_Internet_Hitchhiker 
Larkin, B. (2013). The politics and poetics of infrastructure. Annual Review of Anthropology, Palo Alto, 42, 327-343. https://doi.org/10.1146/annurev-anthro-092412-155522

Latour, B. e Woolgar, S. (1997). A vida de laboratório: a produção dos fatos científicos. Relume Dumará.

Laviolette, P. (2014). Why did the Anthropologist Cross the Road? Hitch-Hiking as a Stochastic Modality of Travel. Ethnos: Journal of Anthropology, 379-401. https://doi.org/10.1080 /00141844.2014.986149

Mahood, L. (2014). Hitchin' a Ride in the 1970s: Canadian Youth Culture and the Romance with Mobility. Histoire sociale / Social History, XLVII(93), 205-227. https://www. researchgate.net/deref/http\%3A\%2F\%2Fdx.doi.org\%2F10.1353\%2Fhis.2014.0021

Medeiros, V. A. S. (2006). Urbis Brasiliae ou sobre cidades do Brasil: inserindo assentamentos urbanos do país em investigações configuracionais comparativa (Tese Doutorado). Universidade de Brasília, Brasília.

Mitchell, T. (1999). Society, economy and the state effect. Em G. Steinmetz (ed.). State/ Culture. State-formation after the cultural turn (pp. 76-97). Cornell University Press.

Neves, Y. R. (2018). Caronas Antropológicas nas ruas de Florianópolis (Dissertação de Mestrado). Universidade Federal do Rio Grande do Sul, Porto Alegre - RS.

Neiburg, F. (2007). As moedas doentes, os números públicos e antropologia do dinheiro. Mana, 13(1), 119-151. http://dx.doi.org/10.1590/S0104-93132007000100005

Perrot, M. (1992). Maneiras de morar. Em M. Perrot (org.). História da vida privada. V. 4: Da Revolução Francesa à Primeira Guerra (pp. 307-323). Companhia das Letras.

Proença, R. L. (2002). Contra-usos e espaço público: notas sobre a construção social dos lugares na Manguetown. Revista Brasileira de Ciências Sociais, 17(49),115-134. https://www.scielo.br/scielo.php?pid=S0102-69092002000200008\&script=sci_ abstract\&tlng $=\mathrm{pt}$

Purkins, J. (2012). Cap. 8. The Hitchhiker as Theorist: Rethinking Sociology and Anthropology from an Anarchist Perspective. Em R. Kinna (ed.). The Continuum Companion to Anarchism (pp.140-161). Continuum International Publishing Group.

Reis, A. F. (2012). Ilha de Santa Catarina: permanências e transformações. Ed. UFSC.

Rial, C. S. (1988). O mar-de-dentro: A transformação do espaço social na Lagoa da Conceição (Dissertação de Mestrado). UFSC, Florianópolis, Brasil.

Rocha, A. L. C. e Neves, Y. R. (2019). A intuição do tempo no estudo antropológico da prática de carona: notas metodológicas de pesquisa. Revista de Estudos e Investigações Antropológicas, 6(2), 46-72. https://periodicos.ufpe.br/revistas/reia/article/view/243526

Schuch, P. (2015). A Legibilidade como Gestão e Inscrição Política de Populações: notas etnográficas sobre a política para pessoas em situação de rua no Brasil. Em C. Fonseca e H. Machado (Org.). Ciência, Identificação e Tecnologias de Governo (pp. 121-145).

Scoot, J. (1998). Seeing Like a State. How Certain Schemes to Improve the Human Condition Have Failed. Yale University Press.

Scoot, J. (2006). City, people and language. Em A. Sharma e A. Gupta (Org.). The Anthropology of the State: a reader (pp. 247-263). Blackwell Publishing.

Smith, M. (2016). Urban infrastructure as materialized consensus. World Archaeology, 48(1), 164-178. https://doi.org/10.1080/00438243.2015.1124804 
Sharma, A. e Gupta, A. (2006). Introduction: Rethinking Theories of the State in an Age of Globalization. Em A. Sharma e A. Gupta (org.), The Anthropology of the State: a reader (pp. 1-43). Blackwell Publishing.

Skinner, Q. (2005). La Liberdad de las repúblicas: ¿Un tecer concepto de libertad? Isegoría, 33. https://doi.org/10.3989/isegoria.2005.i33.417

Simmel, G. (2005). As grandes cidades e a vida do espírito (1903). Mana - Estudos de Antropologia Social, 11(2), 577-591. http://dx.doi.org/10.1590/S0104-93132005000200010

Star, S. (1999). The ethnography of infrastructure. American Behavioral Scientist, Thousand Oaks, 43(3), 377-391. 